\title{
Anatomia do tubo digestivo de Salminus brasiliensis (Cuvier, 1817) (Pisces, Characidae, Salmininae)
}

\author{
Sirlene Souza Rodrigues* \\ Eliane Menin \\ Laboratório de Morfofisiologia Animal, Departamento de Biologia Animal, Centro de Ciências Biológicas e da Saúde, Universidade Federal de Viçosa, \\ CEP 36570-000, Viçosa - MG, Brasil \\ * Rua Arthur Bernardes, 34, apto.44, CEP 36570-000, Centro, Viçosa - MG, Brasil \\ *Autora para correspondência \\ rodrigues.sirlene@gmail.com
}

Submetido em 16/08/2007

Aceito para publicação em 05/04/2008

\section{Resumo}

O tubo digestivo de Salminus brasiliensis (dourado) mostra adaptações anatômicas ao hábito alimentar carnívoro, ictiófago: esôfago e estômago, em especial a região cecal, apresentam-se consideravelmente distensíveis e o intestino relativamente curto. A grande distensibilidade da parede do intestino anterior deve-se, principalmente, ao padrão da mucosa, que apresenta pregas longitudinais. No intestino anterior, a condução do alimento é facilitada pelo padrão longitudinal das pregas da mucosa. No esôfago e na região pilórica, relacionados com a propulsão do alimento para o órgão seguinte, a túnica muscular é mais desenvolvida do que no restante do tubo digestivo. O esfíncter pilórico regula o fluxo do alimento para o intestino médio. Em função do padrão da mucosa dos intestinos médio e posterior, em rede, o material em processamento pode permanecer neles retido por um período maior. A área efetiva de absorção intestinal é ampliada em função da estrutura tubular do intestino médio, das pregas da mucosa e dos cecos pilóricos. O tubo digestivo de $S$. brasiliensis assemelha-se em estrutura ao de outros Salmininae e ao da maioria dos Characiformes ictiófagos como Acestrorhynchus britskii e A. lacustris, embora nestes dois seja encontrada a valva ileorretal; e difere do tubo digestivo de Hoplias malabarius e H. lacerdae, em que o esôfago tem calibre variável, o estômago possui a cárdica mais ampla e o arranjo intestinal é diferente de "N", além da presença da valva ileorretal.

Unitermos: anatomia, tubo digestivo, ictiofagia, Salminus brasiliensis

\section{Abstract}

Anatomy of the alimentary tract of Salminus brasiliensis (Cuvier, 1817) (Pisces, Characidae, Salmininae). The alimentary tract of Salminus brasiliensis shows anatomic adaptations to its carnivorous, ichthyophagous feeding habit, particularly regarding the distensible esophagus and stomach, especially the caecal region, and the 
relatively short intestine. The great distensibility of the wall of the anterior intestine is due mainly to the pattern of the mucous membrane, which exhibits thick longitudinal folds. In the anterior intestine the transport of the food is facilitated by the longitudinal pattern of the mucous folds. In the esophagus and pyloric region, related to the propulsion of food to the net organ, the muscular tunica is more developed than in the rest of the alimentary tract. The pyloric constriction regulates the food flux to the middle intestine. Due to the pattern of mucous membrane of the middle and posterior intestines, in net form, the material being processed can be retained for a greater length of time. The intestinal effective absorption area is amplified due to the tubular structure of the middle intestine, of the mucous intestinal folds, and the pyloric caeca. The alimentary tract of $S$. brasiliensis is similar in structure to that of other Salmininae and to the majority of the piscivorous Characiformes such as Acestrorhynchus britskii and A. lacustris, although in these two the ileum-rectal valve is found. It also differs from the alimentary tracts of Hoplias malabarius and H. lacerdae, in that the esophagus has variable caliber, the stomach possesses a wider cardia, and the intestinal arrangement is different from " $\mathrm{N}$ ", besides the presence of the ileum-rectal valve.

Key words: anatomy, alimentary tract, ichthyophagy, Salminus brasiliensis

\section{Introdução}

Embora de grande importância econômica e sendo exclusivamente sul-americanos (Eigenmann, 1916; Fowler, 1950), os peixes do gênero Salminus têm recebido pouca atenção dos pesquisadores. Dentre os trabalhos sobre os Salmininae ictiófagos (Britski et al., 1986), podem ser destacados os de Mastrarrigo (1949) e Morais-Filho e Schubart (1955) que estudaram o desenvolvimento e a alimentação de $S$. maxillosus, o de Paiva (1959) que fez um estudo preliminar sobre o crescimento, o tubo digestivo e a alimentação de $S$. hilarii e o de Rodrigues e Menin (2006) que descreveram a anatomia da cavidade bucofaringeana de $S$. brasiliensis comparando-a com a de outras espécies ictiófagas.

Uma vez que as informações sobre o aparelho digestório desses peixes são escassas, procurou-se neste trabalho descrever a anatomia do tubo digestivo de $S$. brasiliensis (dourado), discuti-la funcionalmente e estabelecer relações entre a sua estrutura anatômica e os hábitos alimentares da espécie, além de comparar as adaptações do tubo digestivo com aquelas de outras espécies de Teleostei.

\section{Material e Métodos}

Foram utilizados 20 exemplares, machos e fêmeas, de Salminus brasiliensis apresentando 27,5 a $33,6 \mathrm{~cm}$ de comprimento-padrão (valor médio - 30,6 cm) e 344,0 a 527,0 g de peso corpóreo (valor médio - 418,6 g), procedentes da Estação de Hidrobiologia e Piscicultura de Três Marias - CODEVASF, Três Marias - MG.
Após a tomada do peso corpóreo e do comprimento-padrão, o intestino posterior foi seccionado na região anteriormente ao ânus e o aparelho digestório foi perfundido com solução fisiológica para peixes Teleostei de água doce (Hickman, 1967 apud Hoar e Hickman Jr., 1967) para limpeza, e com solução fixadora, solução aquosa de formol a 4\%, para preservação da mucosa. Em seguida, os exemplares foram submersos na solução fixadora, na qual permaneceram durante o período de estudo. Algumas observações tais como coloração e distensibilidade da parede dos órgãos foram feitas anteriormente à fixação.

A preparação dos exemplares para descrição anatômica foi feita conforme Amlacher (1964), fazendo-se uma incisão longitudinal de modo a expor a cavidade peritoneal e permitir, assim, o estudo topográfico dos órgãos do tubo digestivo. A análise da disposição relativa desses órgãos na cavidade peritoneal e a sua descrição anatômica foram feitas conforme os planos anatômicos de delimitação: cranial, caudal, dorsal, ventral e laterais direito e esquerdo.

A divisão do tubo digestivo foi considerada conforme Bértin (1958):

a) Intestino anterior: segmento do aparelho digestivo que compreende o esôfago e o estômago. Seu limite posterior é demarcado pelo esfíncter pilórico e pelos orifícios dos ductos hepatopancreáticos;

b) Intestino médio: segmento do aparelho digestivo que compreende o intestino propriamente dito. Seu limite é demarcado geralmente por uma valva ou, 
mais raramente, pela inserção de uma glândula retal ou pela inserção de cecos;

c) Intestino posterior ou reto: segmento final do aparelho digestivo, que desemboca no ânus.

Ainda, no presente trabalho foi feita a distinção entre intestino posterior e reto, sendo a presença do esfíncter e/ou da valva ileorretal e a modificação do padrão da mucosa consideradas como as condições para que o último segmento do tubo digestivo fosse denominado de reto e não de intestino posterior. Em relação ao intestino médio, cada circunvolução foi designada como alça.

A análise das alterações da forma e dimensões da cavidade peritoneal ao longo do corpo foi feita conforme Menin (1988), sendo alguns exemplares fixados em solução aquosa de formol, a 4\%, congelados e seccionados sagitalmente ou transversalmente. Das secções transversais seriadas, que foram feitas ao longo do corpo, resultaram metâmeros de $1,0 \mathrm{~cm}$ de largura, dos quais foram consideradas ambas as faces, anterior e posterior.

O estudo do padrão da mucosa foi procedido conforme Suyehiro (1942), sendo o tubo digestivo isolado da cavidade peritoneal e incisado longitudinalmente. Após a incisão, as bordas do tubo digestivo foram rebatidas e fixadas, por meio de alfinetes, sobre uma placa de Petri coberta com parafina. $\mathrm{O}$ tubo digestivo foi, então, imerso em água por 24 horas, para evidenciar as pregas da mucosa (Menin, 1988). Posteriormente, a água foi escoada e o tubo digestivo foi secado com papel absorvente para a execução das análises.

A descrição anatômica foi feita com o auxílio de um microscópio estereoscópico Olympus SZH 10 e as figuras que a complementam, com o auxílio de uma câmara clara acoplada ao referido equipamento.

Para fundamentar a discussão funcional do tubo digestivo, foram considerados, em especial, a espessura da parede, a forma e a distensibilidade dos órgãos digestivos, o arranjo e o comprimento do intestino médio. Já o trânsito do alimento foi discutido com base no padrão da mucosa do tubo digestivo e na ocorrência de esfíncteres e valvas (Angelescu e Gneri, 1949; Menin, 1988).

\section{Resultados}

A cavidade peritoneal de Salminus brasiliensis é relativamente pequena, se comparada à massa muscular do peixe. Em secções transversais seriadas, verificouse que, até aproximadamente a região cecal gástrica, a cavidade peritoneal é ovalada, comprimida, e, após essa região, é arredondada e gradativamente de menor diâmetro. Em secção sagital, ela tem forma cônica, mais ampla na porção cranial.

O tubo digestivo ocupa grande parte da cavidade peritoneal, em especial, quando o estômago se encontra em repleção. Os órgãos do tubo digestivo distribuem-se ao longo dessa cavidade e o intestino posterior desemboca no ânus, situado caudalmente.

O esôfago é um órgão tubular, ligeiramente deprimido e curto, situa-se dorsalmente ao coração (Figuras $1 \mathrm{~A}$ e $\mathrm{B})$, é contínuo à faringe e desemboca na região cárdica do estômago (Figura 1C). Após ultrapassar o septo transverso, o esôfago segue um curto trajeto em sentido caudal ao longo do plano sagital, apresentando a mucosa e, em especial, a túnica muscular desenvolvidas. A luz da porção inicial deste órgão, quando contraído, é estreitada pelas pregas da mucosa.

Na mucosa da porção esofágica que precede o septo transverso ocorrem pregas espessas, separadas por profundos e amplos sulcos, sendo cada prega dividida em outras mais estreitas (Figura 2B). Na porção esofágica contida na cavidade peritoneal, as pregas da mucosa são numerosas (em média 15 pregas), espessas com as bordas arredondadas e lisas, longitudinais e contínuas às da porção anteriormente mencionada.

O estômago de S. brasiliensis é do tipo cecal, em Y, com as regiões cárdica e pilórica curtas (Figura 2A). A região cárdica se encontra dorsalmente à região pilórica, possui forma cônica e seu diâmetro é comparativamente maior que o da região pilórica, que é de forma tubular (Figura 2A). Topograficamente a região cárdica está envolvida, cranialmente, pelos lobos hepáticos (Figura 1A, B e C), a sua porção caudal está coberta, ventrolateralmente, à direita e à esquerda, pelos cecos pilóricos (Figura 1A e B); dorsolateralmente, à direita, pelos cecos pilóricos e pela alça 1 do intestino médio (Figura 


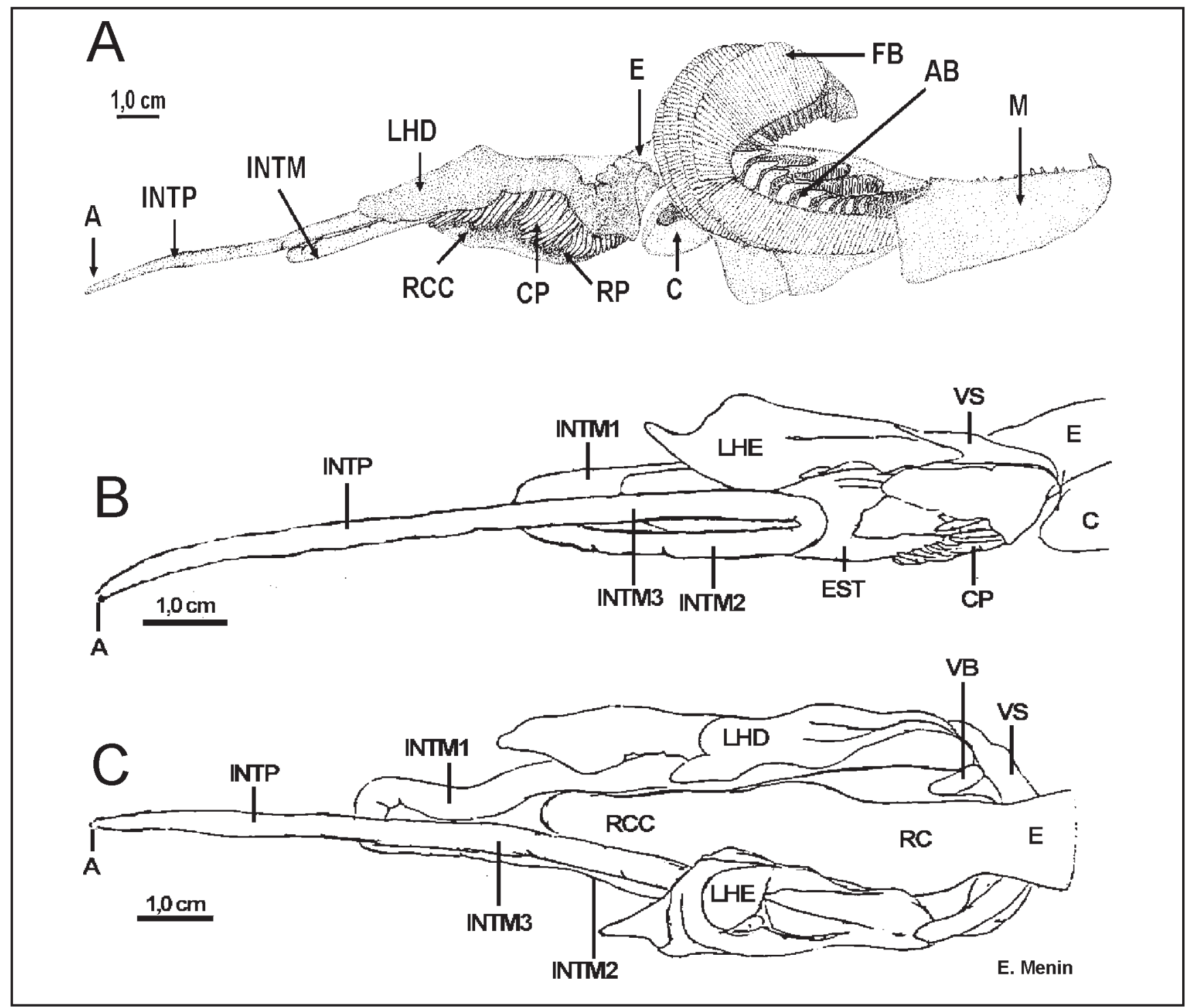

FIGURA 1: Desenho esquemático do aparelho digestório de Salminus brasiliensis. A - Vista lateral direita. B - Vista lateral esquerda; C - Vista dorsal. A: ânus; AB: arcos branquiais; C: coração; CP: cecos pilóricos; E: esôfago; EST: estômago; FB: filamentos branquiais; INTM1, INTM2, INTM3: alças 1, 2 e 3 do intestino médio; INTP: intestino posterior; LHD: lobo hepático direito; LHE: lobo hepático esquerdo; M: mandíbula; RC: região cárdica gástrica; RCC: região cecal gástrica; RP: região pilórica gástrica; VB: vesícula biliar; VS: vaso sangüíneo.

1A); e dorsolateralmente, à esquerda, pelo lobo hepático esquerdo (Figura 1B).

As porções cranial e mediana da região cecal estão acoladas lateralmente, à esquerda, ao lobo hepático esquerdo e às alças 2 e 3 do intestino médio (Figura 1B); lateralmente, à direita, com o lobo hepático direito, vesícula biliar, cecos pilóricos e alça 1 do intestino médio (Figura 1A); e, ventrolateralmente, a região cecal não apresenta topografia com os outros órgãos do aparelho digestório.
A região pilórica está coberta pelos cecos pilóricos (Figura $1 \mathrm{~A}$ ) e, lateralmente, à direita, está acolada à alça 1 do intestino médio. A parede da região pilórica é aparentemente mais espessa e consistente que a das outras regiões gástricas.

A região cárdica apresenta pregas em sua mucosa que são contínuas às do esôfago e estruturalmente semelhantes a essas, embora mais espessas. Os sulcos entre elas são amplos e profundos. As pregas de sua parede ventral, diferentemente das que ocorrem nas paredes 


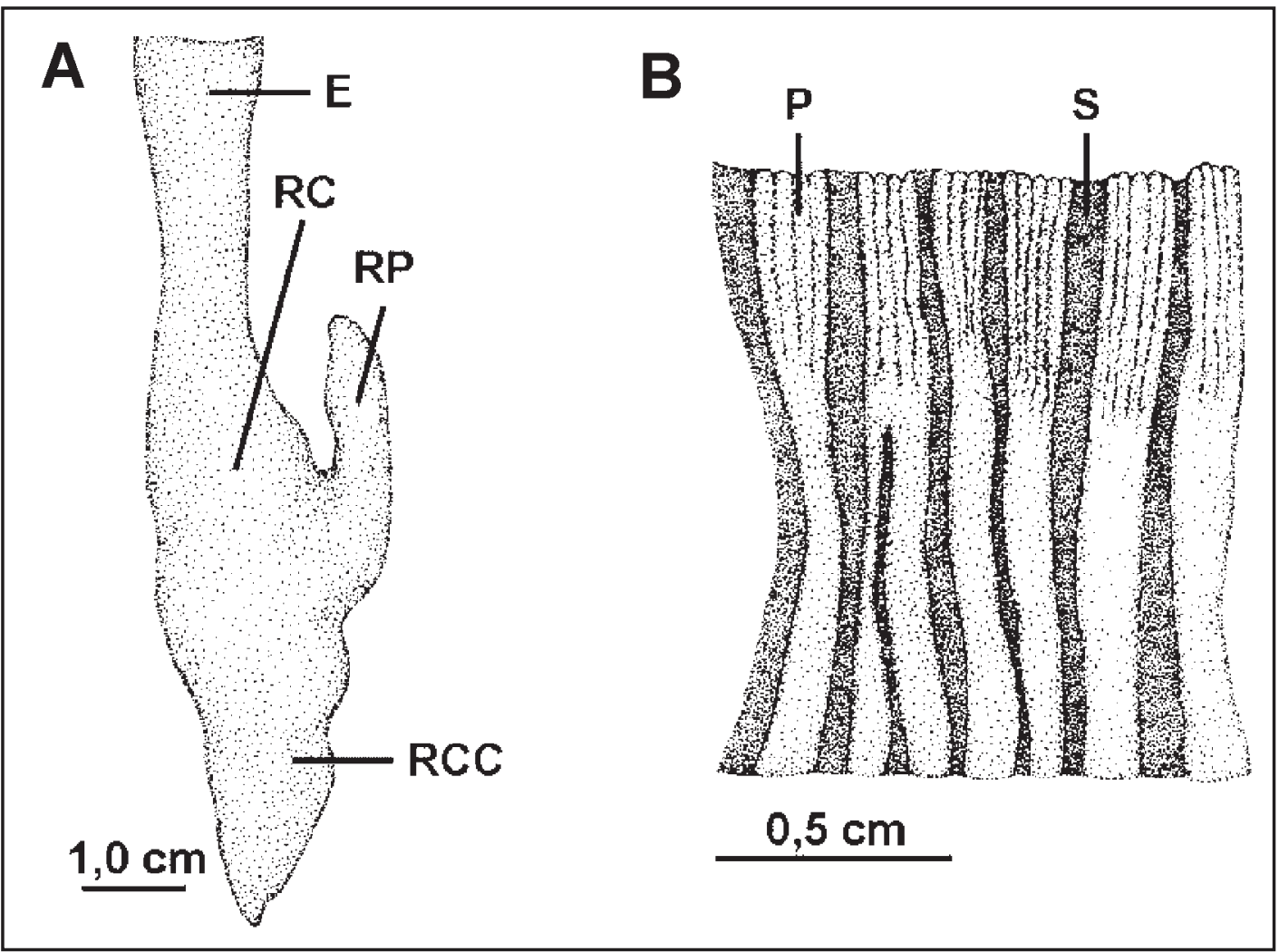

FIGURA 2: Desenho esquemático do intestino anterior (esôfago e estômago) de Salminus brasiliensis. A - Vista lateral direita. B - Mucosa do esôfago. Este órgão foi incisado longitudinalmente em sua parede dorsal e ventral; a mucosa da face lateral direita foi considerada. E: esôfago; P: pregas da mucosa; RC: região cárdica; RCC: região cecal; RP: região pilórica; S: sulcos.

dorsal e laterais, que têm continuidade com as pregas da região cecal, dirigem-se ao orifício de entrada da região pilórica (Figura 3A), sendo continuadas pelas pregas dessa última.

Na região cecal, as pregas da mucosa são ainda mais espessas, de espessura variada e com algumas anastomoses, embora continue predominando o padrão longitudinal (Figura 3A). Como observado na região cárdica, as pregas da parede ventral dirigem-se à região pilórica (Figura 3A). Nesta, as pregas, contínuas às da parede ventral das regiões cárdica e cecal, como foi mencionado anteriormente, são estreitas, pouco espessas, com as bordas arredondadas e lisas (Figura 3B). Os sulcos entre elas são pouco pronunciados.

$\mathrm{Na}$ extremidade cranial da região pilórica, o esfíncter pilórico, constituído pelo espessamento da túnica muscular, acarreta uma pronunciada constrição entre o estômago e o intestino médio. A luz nessa região de transição, já estreita ao longo da região pilórica, fica totalmente obstruída, quando o esfíncter se encontra contraído.

O intestino médio possui forma tubular e, em razão da sua disposição na cavidade peritoneal, pode ser dividido em alças 1, 2 e 3 (Figuras 1A, B e C). A alça 1 tem início imediatamente após o esfíncter pilórico e se dispõe no antímero direito dessa cavidade. Com trajeto linear, segue em sentido caudal até ultrapassar a região cecal gástrica. Curvando-se em direção ao antímero esquerdo, por meio de uma flexão acentuada, dá início à alça 2 , que tem sentido cranial, e chega até o início da região pilórica. Neste local, a alça 2 sofre flexão em sentido dorsal, permanecendo no mesmo antímero. $\mathrm{O}$ intestino médio, agora alça 3 , segue linearmente em sentido caudal, dorsalmente à alça 2. Em conjunto, as alças do intestino médio dispõem-se em forma de "N".

O intestino médio, exceto na sua porção inicial, da 


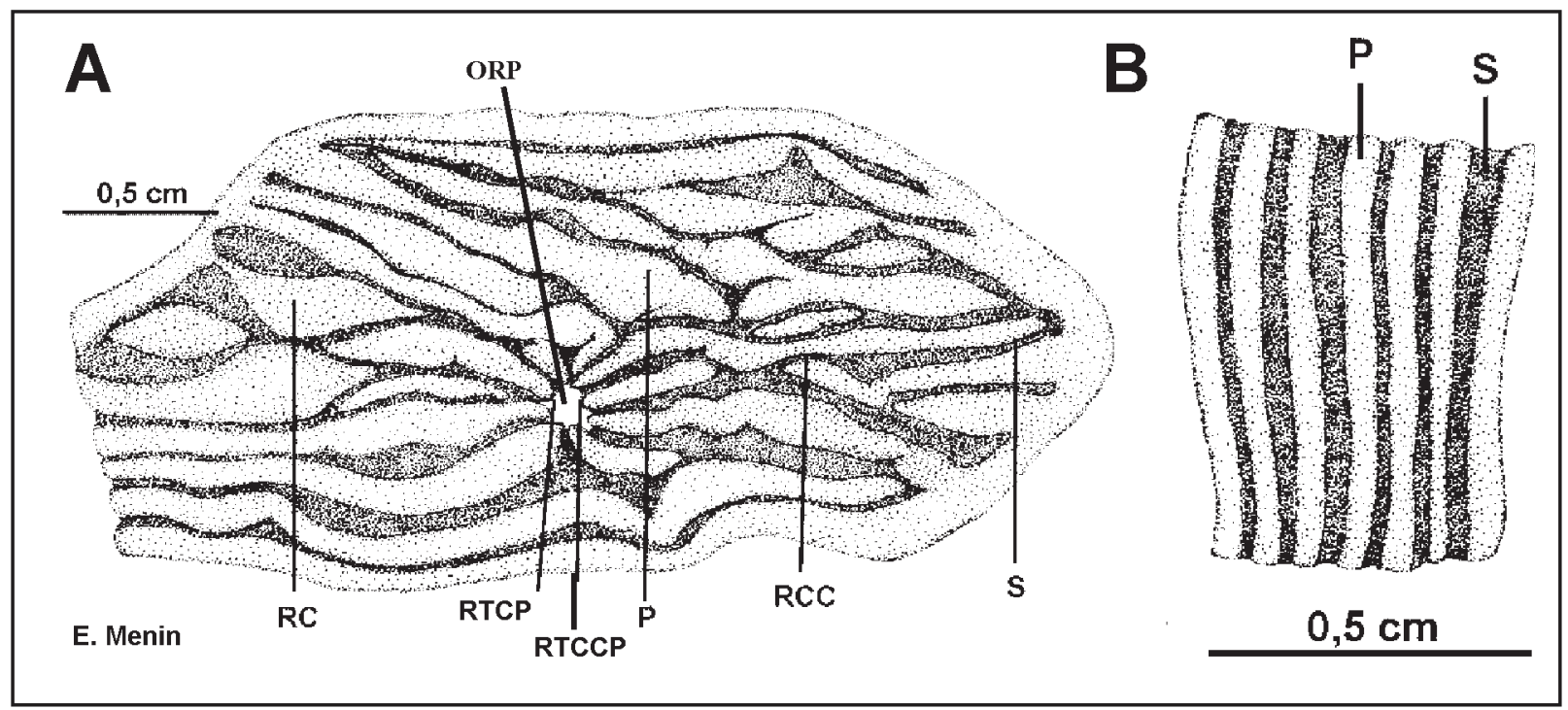

FIGURA 3: Desenho esquemático da mucosa gástrica de Salminus brasiliensis. A: Mucosa das regiões cárdica e cecal. O estômago foi incisado longitudinalmente em sua parede dorsal e as paredes laterais foram refletidas. B: Mucosa da região pilórica. A região pilórica foi incisada longitudinalmente em sua parece dorsal e ventral; a mucosa da face lateral direita foi considerada. ORP: orifício de entrada da região pilórica; P: prega; RC: região cárdica; RCC: região cecal; RTCP: região de transição entre a cárdica e a pilórica; RTCCP: região de transição entre a cecal e a pilórica; S: sulco.

qual se evaginam os cecos pilóricos, mantém aproximadamente o mesmo calibre ao longo de sua extensão. O intestino posterior, que continua o intestino médio sem interrupção por constrição ou valva, após curto trajeto dorsiventrocaudal, desemboca no ânus (Figura 1A, B e C).

O padrão da mucosa dos intestinos médio (Figura 4A, B e C) e posterior (Figura 4D) é em rede, predo- minantemente longitudinal. Nas alças 2 (Figura 4B) e 3 (Figura 4C) do intestino médio, as pregas são ligeiramente mais espessas e largas do que na alça 1 (Figura 4A). No intestino posterior, elas são mais delgadas e estreitas (Figura 4D), tornando-se o padrão da mucosa, próximo ao ânus, longitudinal, constituído por pregas delgadas e estreitas, de bordas arredondadas.

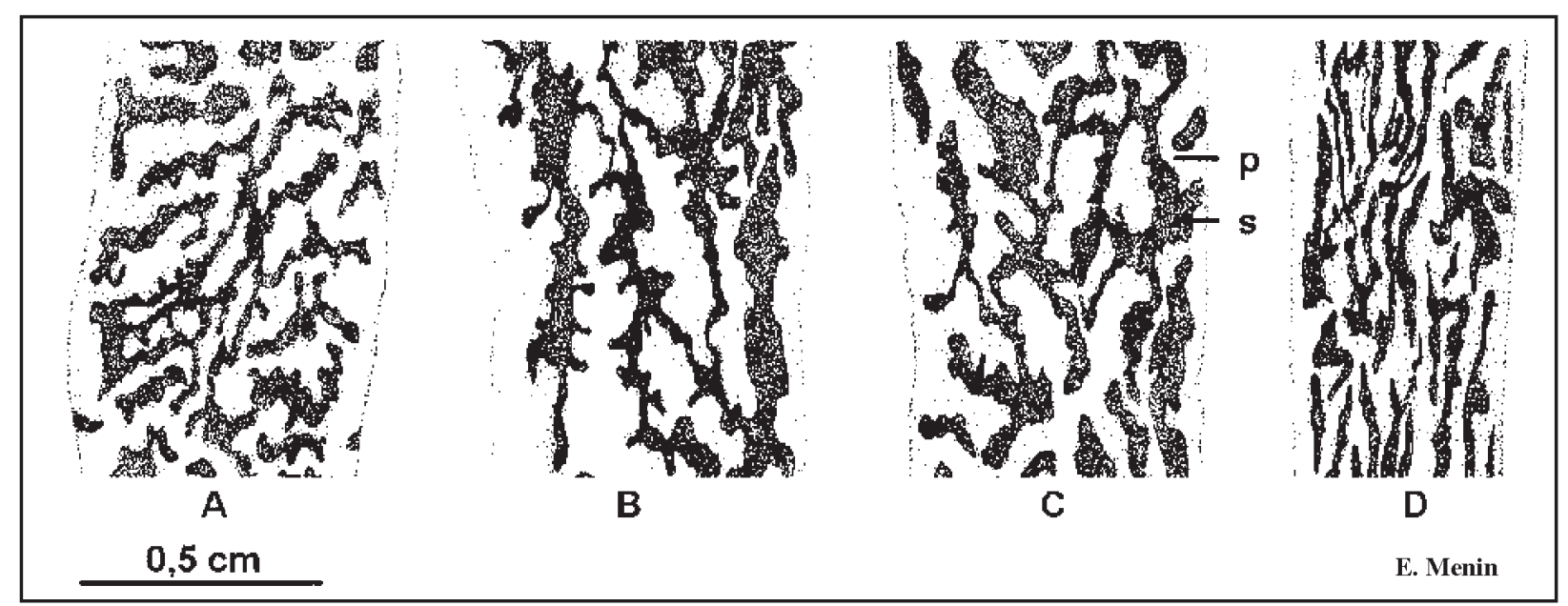

FIGURA 4: Desenho esquemático da mucosa intestinal de Salminus brasiliensis. Os intestinos foram incisados longitudinalmente em sua parede dorsal. A: alça 1 do intestino médio; B: alça 2 do intestino médio; C: alça 3 do intestino médio; D: intestino posterior; P: pregas: S: sulcos. 
A partir do esfíncter pilórico até a porção mediana da alça 1 do intestino médio, são verificadas evaginações intestinais cilíndricas e de ápice cônico, os cecos pilóri$\cos$ (Figura 1A e B). Na extremidade cranial do intestino médio, os cecos pilóricos, numerosos e próximos uns dos outros, evaginam-se da parede dorsal intestinal e contornam a região pilórica, cobrindo totalmente suas paredes direita, esquerda, dorsal e parcialmente, a ventral. Nas porções cranial e mediana da alça 1 do intestino médio, os cecos pilóricos originam-se da parede ventral do intestino e se dirigem ventrocaudalmente, recobrindo a parede direita do estômago (regiões cárdica, pilórica e parte da região cecal). Os cecos pilóricos estão unidos em sua base, evaginando-se dois ou três de um mesmo ramo basal, que se comunica com a luz intestinal por meio de um orifício. Os apêndices originados de um mesmo ramo basal podem ter diferentes comprimentos embora apresentem forma semelhante.

As pregas da mucosa dos cecos pilóricos são delgadas, sinuosas, com bordas arredondadas, anastomosadas e separadas por sulcos profundos. Em conjunto, o padrão da mucosa lembra uma rede na qual predomina a direção longitudinal (Figura 5).

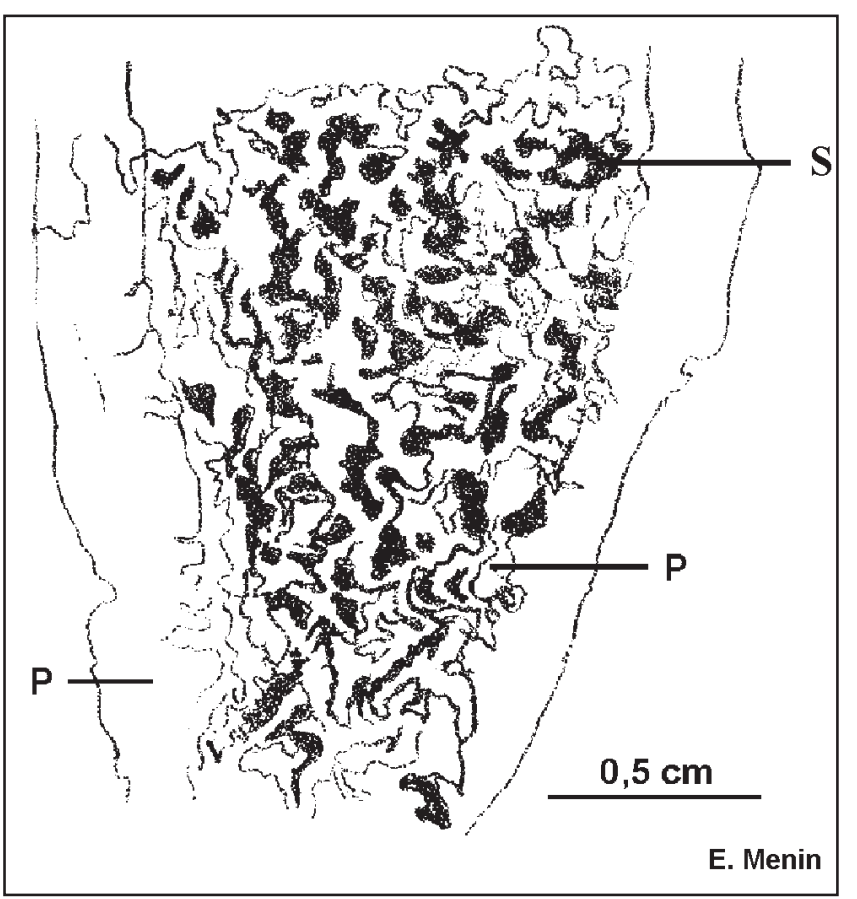

FIGURA 5: Desenho esquemático da mucosa de um dos cecos pilóricos, incisado longitudinalmente, de Salminus brasiliensis. P: pregas; S: sulcos.

\section{Discussão}

Em Salminus brasiliensis, a forma e o tamanho da cavidade peritoneal, como em outros peixes (Suyehiro, 1942; Menin, 1988), são condizentes com a forma do corpo, a qual, por sua vez, como foi destacado anteriormente por Nikolsky (1963) e Keast e Webb (1966) em outras espécies, está relacionada com o hábitat e com a ecologia alimentar.

Segundo Romer e Parsons (1986), nos Elasmobranchii e na maior parte dos peixes com nadadeiras raiadas, diferentemente dos demais peixes, existe um órgão, o estômago, e uma área curta e mal definida, anterior a ele, que pode ser considerada como esôfago. No entanto, foi verificado que o esôfago de $S$. brasiliensis é um órgão definido, embora curto. Havendo, como mencionado anteriormente, uma diferença de calibre entre o esôfago e o estômago. Esse mesmo aspecto estrutural tem sido observado em outros Characiformes carnívoros como Hoplias malabaricus (Menin e Mimura, 1993b), H. lacerdae (Gomide, 1996), Acestrorhynchus britskii e A. lacustris (Amaral, 1990), bem como em outros Teleostei de diferentes hábitos alimentares, como nos Characiformes onívoros Leporinus reinhardti, Brycon lundii (Menin e Mimura, 1993b) e L. macrocephalus (Rodrigues et al., 2004) e nos Siluriformes onívoros Pimelodus sp. (Menin e Mimura, 1993b) e Conorhynchus conirostris (Rodrigues et al., 2002). O esôfago de $S$. brasiliensis possui calibre constante ao longo do seu comprimento, assim como o das espécies mencionadas anteriormente, exceto os Erythrinidae, em que o calibre deste órgão é variável, sendo mais amplo na porção cranial. Ainda, existem espécies carnívoras com esôfago diferenciado e relativamente longo, como no Gymnotoidei Gymnotus carapo (Menin, 1989).

Embora em muitos peixes possa ser encontrado um esfíncter entre o esôfago e o estômago (Romer e Parsons, 1986), em $S$. brasiliensis, como em outros Teleostei (Blake, 1930; Bishop e Odense, 1966; Menin, 1988; Amaral, 1990; Rodrigues et al., 2002; Rodrigues et al., 2004), independentemente do hábito alimentar, é observada a continuidade anatômica desse órgão com o estômago.

Também, como na maioria dos Teleostei (Menin, 1988; Amaral, 1990; Rodrigues et al., 2002; Rodrigues 
et al., 2004), o padrão da mucosa esofágica desta espécie é longitudinal, o que pode ser relacionado com a distensibilidade da parede desse órgão, o que o torna adequado para a recepção e rápida condução de presas inteiras ao estômago. Lagler et al. (1977) ressaltaram a capacidade de distensão que o esôfago possui, em particular nas espécies ictiófagas, que deglutem presas inteiras, como uma das adaptações que os peixes apresentam para desempenharem com eficiência o ato de se alimentar. Em Salminus brasiliensis, o padrão de pregas da mucosa possivelmente auxilia nos processos de deglutição, contribuindo para que o trânsito do alimento até o estômago seja rápido.

Em S. brasiliensis, outras adaptações anatômicas que também possibilitam a ingestão e deglutição de presas inteiras foram verificadas por Rodrigues e Menin (2006) no intestino cefálico: fenda bucal ampla, cavidade bucal alargada aboralmente e aparelho dentário faringeano com espessura reduzida, o que favorece a tomada e a ingestão de presas de maior porte; as dentições oral e faringeana, com dentes pontiagudos e encurvados, juntamente com a língua relativamente móvel, previnem o escape da presa; e a ausência de relevos pronunciados na mucosa facilita o trânsito do alimento.

Quanto ao estômago, alguns autores (Mohsin, 1962; Verma et al., 1974) procuraram estabelecer relações entre a anatomia deste órgão e os hábitos alimentares. Mohsin (1962) afirmou que o estômago toma formas diferentes segundo a natureza da dieta, podendo ser considerado como o órgão do aparelho digestório que mostra as mais pronunciadas adaptações e correlações com ela. Dentre as espécies predadoras, ictiófagas, podem ocorrer diferentes adaptações do estômago, as quais se referem principalmente ao tamanho das regiões cárdica e cecal. Por exemplo, em H. malabaricus a região cárdica é a região mais ampla, enquanto em $A$. britskii e $A$. lacustris a região cecal é a que apresenta maiores dimensões quando comparada às demais regiões gástricas (Menin e Minura, 1993a). Já em G. carapo, embora a região cecal seja a maior dentre as regiões gástricas, o estômago como um todo é reduzido (Menin, 1989).

Em S. brasiliensis é, em particular, a região cecal, a maior e mais distensível, que permite a adaptação gástrica à ingestão de presas inteiras. Em S. maxillosus, espécie com estômago anatomicamente semelhante ao de $S$. brasiliensis, a parede do estômago é espessa porém elástica e resistente, o que permite ao peixe capturar presas de grande porte, de 1/3 a 1/2 do comprimento do seu corpo (Morais-Filho e Schubart, 1955). Conforme Zihler (1982), a distensibilidade do estômago pode ser interpretada como um efeito adaptativo aos hábitos ictiófagos. Essa característica, que capacita a região cecal gástrica de $S$. brasiliensis a atuar como local de armazenamento do material deglutido, pode ser efetivada em virtude da ocorrência de pregas espessas e predominantemente longitudinais na sua mucosa, como também observado em A. britskii e A. lacustris (Menin e Minura, 1993a).

A região pilórica de S. brasiliensis, como a de outras espécies Teleostei de diferentes hábitos alimentares (Menin, 1988; Menin, 1989; Menin e Mimura, 1992b; Menin e Mimura, 1993a; Rodrigues et al., 2002; Rodrigues et al., 2004), em virtude de sua forma, de suas dimensões, do padrão de pregas de sua mucosa e, em particular, da espessura de sua parede, está relacionada principalmente com o esvaziamento gástrico, ou seja, com a transferência do material já processado para o intestino médio.

Assim, quanto à condução do alimento pelo intestino anterior, pode-se ressaltar que as pregas da mucosa desse segmento contribuem para transportá-lo ao estômago e deste ao intestino médio, quando digerido. Essa afirmação pode ser feita em razão da arquitetura da mucosa, na qual as pregas são contínuas, desde o início do esôfago até a região pilórica.

Segundo Owen (1866), embora o estômago dos peixes seja uma única e comumente ampla câmara, há uma desproporção entre os diâmetros dos orifícios cárdico e pilórico. De fato, nesta espécie, o orifício cárdico é mais amplo, praticamente acompanhando a luz da extremidade caudal esofágica. O orifício pilórico, por sua vez, é estreito. Entretanto, não se deve estabelecer relação entre a presença dessa estrutura e o hábito alimentar carnívoro de $S$. brasiliensis, uma vez que ela ocorre em espécies carnívoras (Blake, 1930; Mohsin, 1962; Bucke, 1971; Menin, 1988, Menin, 1989; Amaral, 1990; Menin e Mimura, 1993a), planctófagas (Khanna e Mehrotra, 1971; Reifel e Travill, 1978), onívoras (Mohsin, 1962; Menin, 1988; Menin e Mimura, 1992b; Rodrigues et al., 2002; 
Rodrigues et al., 2004), iliófagas (Blake, 1936; Menin, 1988) e herbívoras (Pasha, 1964). A função atribuída ao esfíncter pilórico é o controle da passagem do alimento para o intestino médio (Sis et al., 1979; Menin, 1988; Rodrigues et al., 2002; Rodrigues et al., 2004).

Como foi ressaltado em estudos anteriores (Menin, 1988, Menin, 1989; Amaral, 1990; Menin e Mimura, 1992a; Menin e Mimura, 1993c), o padrão de enrolamento intestinal depende do comprimento do intestino. Essas duas características, por sua vez, devem ser compatíveis com a forma do corpo, da cavidade peritoneal e com o desenvolvimento da bexiga natatória e da musculatura corpórea (Bértin, 1958). Na espécie em estudo, como nos ictiófagos $S$. maxillosus (Morais-Filho e Schubart, 1955), A. britskii e A. lacustris (Amaral, 1990), que apresenta corpo comprimido, o padrão de enrolamento intestinal em "N" foi mantido, com variações mínimas, nos exemplares analisados. Um arranjo intestinal diferente deste foi observado em outros ictiófagos, como $H$. malabaricus (Menin e Mimura, 1992a) e H. lacerdae (Gomide, 1996), espécies em que a primeira alça desse segmento dispõe-se ao longo da face esquerda da região cárdica, em razão da disposição posterior da região pilórica. O padrão em "N" é mais comumente encontrado nos onívoros, como Leporinus reinhardti (Menin e Mimura, 1993c) e L. macrocephalus (Rodrigues et al., 2004).

Khanna e Mehrotra (1971) verificaram maior complexidade do padrão da mucosa no intestino médio de espécies carnívoras. Entretanto, Sinha e Moitra (1975) afirmaram ter observado um padrão mais complexo nos herbívoros e Menin (1988) e Menin et al. (2006) o verificaram nos iliófagos. Em $S$. brasiliensis, as pregas da mucosa dos intestinos médio e posterior são complexas, tanto quanto em $H$. malabaricus, padrão ao qual se assemelha. Porém, como nessa última espécie, o padrão de S. brasiliensis é menos complexo do que o observado em espécies iliófagas, como Prochilodus marggravii e P. affinis (Menin, 1988; Menin et al., 2006).

O padrão da mucosa intestinal tem também sido relacionado com o transporte do alimento (Moitra e Sinha, 1971; Menin, 1988; Rodrigues et al., 2002; Rodrigues et al., 2004; Menin et al., 2006). O padrão da mucosa dos intestinos médio e posterior de $S$. brasiliensis, em rede, predominantemente longitudinal, deve, além de possi- bilitar a distensão desses órgãos para a acomodação do material que recebe, contribuir para a sua retenção por um período maior, retardando o seu avanço no sentido crânio-caudal. Este fato é de expressiva importância para os processos digestivos e absortivos, uma vez que nesta espécie não ocorrem o esfíncter e a valva ileorretais, diferentemente do que é verificado em outras espécies ictiófagas como G. carapo (Menin, 1989), H. malabaricus (Menin e Mimura, 1992a), H. lacerdae (Gomide, 1996), A. britskii e A. lacustris (Amaral, 1990), em que o esfíncter e a valva ileorretais compartimentalizam o intestino em dois segmentos, intestino médio e reto, e regulam o fluxo do alimento entre esses segmentos.

Para $S$. brasiliensis, da mesma forma que para $S$. maxillosus (Mastrarrigo, 1949), pode-se afirmar que no aparelho digestório ocorrem várias adaptações anatômicas ao hábito alimentar carnívoro, ictiófago, sendo, no tubo digestivo, a estrutura do estômago e o comprimento do intestino as mais expressivas.

Dentre as formas de ampliação da área superficial do intestino, propostas por Romer e Parsons (1986), em $S$. brasiliensis podem ser encontrados: (1) intestino tubular e delgado; e (2) pregas na mucosa intestinal. Além disso, os cecos pilóricos constituem outro artifício estrutural para esta espécie ampliar a área intestinal. $\mathrm{Na}$ maioria dos Teleostei ictiófagos como G. carapo (Menin, 1989), H. malabaricus (Menin e Mimura, 1992a), $H$. lacerdae (Gomide, 1996), A. britskii e A. lacustris (Amaral, 1990), os cecos pilóricos estão presentes, embora com disposição, forma e número próprios. Entretanto, outros peixes onívoros, preferencialmente carnívoros, como algumas espécies de Pimelodidae (Menin e Mimura, 1992a; Seixas Filho, 1998), não possuem cecos pilóricos.

\section{Referências}

Amaral, A. A. 1990. Anatomia comparativa do aparelho digestório de Acestrorhynchus britskii Menezes, 1969 e Acestrorhynchus lacustris Reinhardt, 1874 (Pisces, Characidae, Acestrorhynchidae). Revista Ceres, 37 (212): 277-288.

Amlacher, E. 1964. Manual de enfermedades de los peces. Acribia, Zaragoza, España, 319pp.

Angelescu, V.; Gneri, F. S. 1949. Adaptaciones del aparato digestivo al régimen alimenticio en algunos peces del rio Uruguay e del rio de la Plata. Revista del Museo Argentino de Ciencias Naturales 
"Bernardino Rivadavia" e Instituto Nacional de Investigacion de las Ciencias Naturales (Argentina), Zoología, 1 (6): 161-272.

Bértin, L. 1958. Appareil digestif. In: Grassé, P. P. (ed.). Traité de Zoologie. v.13. Masson, Paris, França, p.1249-1301.

Bishop, C.; Odense, P. H. 1966. Morphology of the digestive tract of the cod Gadus mohua. Journal of the Fisheries Research Board of Canada, 23 (10): 1607-1615.

Blake, I. H. 1930. Studies on the comparative histology of the digestive tube of certain teleost fishes. I. A predaceous fish, the seabass, Centropristis striatus. Journal of Morphology, 50: 39-70.

Blake, I. H. 1936. Studies on the comparative histology of the digestive tube of certain teleost fishes. II. A bottom feeding fish, the sea-robin, Prionotus carolinus. Journal of Morphology, 60 (1): 77 102.

Britski, H. A.; Sato, Y.; Rosa, A. B. S. 1986. Manual de identificação de peixes da região de Três Marias. $2^{\mathrm{a}}$ ed. Câmara dos Deputados, Coordenação de Publicações - CODEVASF, Divisão de Piscicultura e Pesca, Brasília, Brasil, 115pp.

Bucke, D. 1971. The anatomy and histology of the alimentary tract of the carnivorous fish, the pike Esox lucius L. Journal of Fish Biology, 3 (4): 21-431.

Eigenmann, C. H. 1916. On the species of Salminus. Annals of Carnegie Museum, 10: 91-92.

Fowler, H. W. 1950. Os peixes de água doce do Brasil. Arquivos de Zoologia, 6: 1-625.

Gomide, A. T. H. 1996. Anatomia funcional e morfometria comparativas do tubo digestivo de trairão (Hoplias cf. lacerdae Ribeiro, 1908) (Characiformes, Erythrinidae), em diferentes classes de tamanho. Dissertação de Mestrado, Universidade Federal de Viçosa, Brasil, 76pp.

Hoar, W. S.; Hickman Jr., C. P. 1967. General and Comparative Physiology. Prentice-Hall, New Jersey, USA, 296pp.

Keast, A.; Webb, D. 1966. Mouth and body form relative to feeding ecology in the fish fauna of small lake, Lake Opinicon, Ontario. Journal of the Fisheries Research Board of Canada, 23: 18451874.

Khanna, S. S.; Mehrotra, B. K. 1971. Morphology and Histology of the teleostean intestine. Anatomischer Anzeiger, 1295: 1-18.

Lagler, K. F.; Bardach, J. E.; Miller, R. R.; Passino, D. R. M. 1977. Ichthyology. John Wiley, New York, USA, 506pp.

Matrarrigo, V. 1949. El dorado. El Ministerio de Agricultura y Ganado, La División de cultivo del Pez, Pesca y Caza Marina, Buenos Aires, Argentina, 19pp.

Menin, E. 1988. Anátomo-histologia funcional comparativa do aparelho digestório de seis Teleostei (Pisces) de água doce. Tese de Doutorado, Universidade de São Paulo, Brasil, 557pp.

Menin, E. 1989. Anatomia funcional do tubo digestivo de Gymnotus carapo Linnaeus, 1758 (Siluriformes, Gymnotoidei, Gymnotidae). Revista Ceres, 36 (207): 435-457.

Menin, E.; Mimura, O. M. 1992a. Anatomia comparativa do intestino de duas espécies de peixes Teleostei de hábitos alimentares distintos. Revista Ceres, 39 (224): 308-341.

Menin, E.; Mimura, O. M. 1992b. Anatomia funcional comparativa do estômago de três peixes Telestei de hábito alimentar onívoro. Revista Ceres, 39 (223): 233-260.
Menin, E.; Mimura, O. M. 1993a. Anatomia comparativa do estômago de três peixes Teleostei de água-doce de hábito alimentar ictiófago. Revista Ceres, 40 (228): 203-222.

Menin, E.; Mimura, O. M. 1993b. Anatomia comparativa do esôfago de seis peixes Teleostei de água doce de distintos hábitos alimentares. Revista Ceres, 15 (230): 334-369.

Menin, E.; Mimura, O. M. 1993c. Anatomia funcional comparativa do intestino de dois peixes Teleostei de água doce de hábito alimentar onívoro. Revista Ceres, 15 (231): 450-478.

Menin, E.; Rodrigues, S. S.; Mimura, O. M. 2006. Anatomia do intestino de Prochilodus marggravii (Walbaum, 1792) e Prochilodus affinis (Reinhardt, 1874) (Characiformes: Prochilodontidae), de hábito alimentar iliófago. Resumo expandido do IV Congreso Iberoamericano Virtual de Acuicultura, Zaragoza, España, p.3249. Disponível em $<$ http://www.civa2006.org $>$

Mohsin, S. M. 1962. Comparative morphology and histology of the alimentary canals in certain groups of Indian teleosts. Acta Zoologica, 43 (1): 79-133.

Moitra, S. K.; Sinha, G. M. 1971. Studies on the morphohistology of the alimentary canal of a carp, Chagunius chagunio (Hamilton) with reference to the nature taste buds and mucous cells. Journal of the Inland Fisheries Society of India, 3: 44-56.

Morais-Filho, M. B.; Schubart, O. 1955. Contribuição ao estudo do dourado (Salminus maxillosus Val.) do rio Mogi Guassu (Pisces, Characidae). Ministério da Agricultura. Divisão de Caça e Pesca, São Paulo, Brasil, 131pp.

Nikolsky, G. V. 1963. The ecology of fishes. Academic Press, London, UK, 325pp.

Owen, R. 1866. Anatomy of vertebrates. v.1, Green, London, UK, 650pp.

Paiva, M. P. 1959. Notas sobre o crescimento, o tubo digestivo e a alimentação da gitubarana, Salminus hilarii Val., 1829 (Pisces, Characidae). Boletim do Museu Nacional, Nova Série de Zoologia, 196: 1-13.

Pasha, S. M. K. 1964. The anatomy and histology of the alimentary canal of a carnivorous fish Megalops cyprinoides. Proceedings of the National Academy of Sciences India, 60B: 107-115.

Reifel, C. W.; Travil, A. A. 1978. Gross morphology of the alimentary canal in 10 teleostean species. Anatomischer Anzeiger, 144: 441-449.

Rodrigues, S. S.; Menin, E. 2006. Anatomia da cavidade bucofaringeana de Salminus brasiliensis (Cuvier, 1817) (Pisces, Characidae, Salmininae). Biotemas, 19 (1): 41-50.

Rodrigues, S. S.; Navarro, R. D.; Menin, E. 2004. Anatomia do tubo digestivo de Leporinus macrocephalus Garavello \& Britski, 1988 (Characiformes, Anostomidae). Resumo expandido do III Congreso Iberoamericano Virtual de Acuicultura, Zaragoza, España, p. 333-342. Disponível em <http://www.civa2004.org>

Rodrigues, S. S.; Oliveira, A. L. S.; Menin, E. 2002. Anatomia funcional do tubo digestivo de Conorhynchus conirostris (Valenciennes, 1840) (Siluriformes, Pimelodidae). Anais do $24^{\circ}$ Congresso Brasileiro de Zoologia, Itajaí, Brasil, p.293.

Romer, A. S.; Parsons, T. S. 1986. The vertebrate body. CBS and Saunders, Philadelphia, USA, 679pp.

Seixas Filho, J. T. Anatomia funcional e sistemas enzimático e endócrino do intestino de Teleostei (Pisces) de água doce com 
hábitos alimentares distintos. Tese de Doutorado, Universidade Federal de Viçosa, Brasil, 175pp.

Sinha, G. M.; Moitra, S. K. 1975. Functional morpho-histology of the alimentary canal of the Indian freshwater major carp Labeo rohita (Ham) during its different life-histology stages. Anatomischer Anzeiger, 38: 222-239.

Sis, R. F.; Ives, P. J.; Jones, D. M.; Lewis, D. H.; Haensly, W. E. 1979. The microscopic anatomy of the esophagus, stomach and intestine of the channel catfish, Ictalurus punctatus. Journal of Fish Biology, 14: 179-186.
Suyehiro, Y. A. 1942. A study of the digestive system and feeding habits of fish. Japanese Journal of Zoology, 10: 1-303.

Verma, S. R.; Tyagi, M. P.; Dalela, R. C. 1974. Morphological variations in the stomachs of a few teleost fishes in relation to food and feeding habits. Gegenbaurs Morphologisches Jahrbuch, 120 (3): 36-380.

Zihler, F. 1982. Gross morphology and configuration of digestive tracts of Cichlidae (Teleostei, Perciformes): Phylogeny and functional significance. Netherlands Journal of Zoology, 32 (4): 544571. 